\title{
Contrainformação e conhecimento emancipatório como práticas educativas no enfrentamento da economia de desastres da mineração em Barcarena (PA).
}

\section{Counterintelligence and emancipatory knowledge as educational practices in facing the mining disaster economy in Barcarena (PA).}

Resumo: A crise ambiental sob a hegemonia da mineração em Barcarena provocou a recomposição do campo político. Este artigo faz uma análise da atuação dos movimentos sociais na produção social da contrainformação no contexto da economia de desastre. São apresentadas as principais tensões em torno da disputa narrativa e as estratégias de resistências. De um modo geral, há uma importante insurgência política no campo de informações na medida em que os atores atingidos estão se apropriando de outros conhecimentos que vem potencializando as resistências e à defesa dos ecossistemas duramente atingidos. O conjunto destas ações pautam práticas educativas na formação de sujeitos políticos com caráter emancipatório, cujo foco é a garantia de direitos socioterritoriais para os povos da Amazônia. A abordagem interdisciplinar colabora na apreensão da arena de disputa, em especial, a politização do tema desastres, ampliando a análise dos mesmos, rompendo com a visão tecnicista agenciada pelas mineradoras.

Palavra-chave: Contrainformação. Desastres. Disputa Política.

Abstract: The environmental crisis under the hegemony of mining in Barcarena provoked the recomposition of the political field. This article analyzes the role of social movements in the social production of counter-information in the context of the disaster economy. Tensions around the narrative dispute and resistance

\footnotetext{
* Possui graduação em Administração pela Universidade Federal do Pará (1993), mestrado em Planejamento do Desenvolvimento pelo Núcleo de Altos Estudos Amazônicos (NAEA/UFPA, 1998), Doutorado em Educação pela Pontifícia Universidade Católica do Rio de Janeiro e PósDoutorado em Desenvolvimento Socioambiental do Programa de Pós-Graduação em Desenvolvimento Sustentável do Trópico Úmido (PPGDSTU) pelo NAEA/UFPA. É professor Adjunto do Curso de Serviço Social e Coordenador de Pós-Graduação e Pesquisa da UFPACampus Marajó Breves. Foi professor e coordenador do Curso de Administração do Centro Universitário do Estado do Pará (CESUPA). Integrante do Grupo pesquisa GETTAM (Grupo de Pesquisa sobre Estado, Território, Trabalho e Mercados Globalizados na Amazônia).
} 
strategies are presented. In general, there is an important political insurgency in the field of information, as the affected actors are appropriating other knowledge that has been potentiating the resistance and defense of the hard-hit ecosystems. The set of these actions guide educational practices in the emancipatory formation of political subjects, whose focus is the guarantee of socio-territorial rights for the peoples of the Amazon. The interdisciplinary approach contributes to the apprehension of the dispute arena, in particular, the politicization of the topic of disasters, expanding their analysis, breaking with the technicist vision managed by the mining companies.

Keyword: Counter-Information. Disasters. Political Dispute.

\section{Introdução}

Estudos anteriores ${ }^{1}$ apontaram como os processos de resistência no município Barcarena forjaram uma consciência política que foi base para incremento de novas estratégias de resistência dos movimentos sociais. Por outro lado, a recorrência de desastres capitaneou a insurgência contra o sistema de mineração que aprisiona historicamente o município num ciclo de destruição e morte.

O Movimento pela Soberania Popular na Mineração (MAM) é um dos exemplos da diversidade de entidades do campo democrático-popular, cuja matriz é a defesa da vida e florestas como direito territorial de continuarem vivendo como povos da Amazônia. Na mesma direção, o Movimento Atingidos por Barragens (MAB) promoveu em 2019 Jornadas de Lutas com foco na produção de informações, organização de lutas e mobilização para avançar na justiça aos grupos de atingidos. O MAM e MAB são entidades nacionais com representação regional no Pará e em Barcarena e ambos têm ações integradas com o Movimento Barcarena Livre de atuação local. Este último formado por diversos segmentos da sociedade barcarenense (trabalhadores/as, comunidades

\footnotetext{
${ }^{1}$ Há um grupo de autores que, mais recentemente, vem se debruçando sobre as formas de resistência dos movimentos sociais e as transformações do campo político como área de disputa: Carmo, Castro e Patrício (2015), Castro (2017), Carmo (2017), Carmo, Hazeu, Costa e Fialho Nascimento (2017), Hazeu, Costa e Fialho Nascimento (2019) e Carmo e Castro (2019).
} 
tradicionais, sindicalistas e estudantes) com objetivo de ampliar a organização social e resistência política diante do contexto de destruição e mortes em Barcarena.

A opção política dos movimentos sociais pela radicalidade em associar mineração com desastres e afirmar que o emprego não pode ser à custa da destruição do meio-ambiente recompôs o campo de disputa na região. O contexto histórico de Barcarena como distrito industrial está na visão políticogovernamental, estrategicamente, relacionada com a ideia da minériodependência que impõe ao município a condição de subserviência ao sistema de mineração. O “discurso do desenvolvimento minerador" (COELHO, 2012) impõe a condição de geração de emprego como um dos principais vetores de legitimação. No entanto, "são pouquíssimos empregos diretos criados, que geralmente exigem mão de obra altamente qualificada inexistente nas regiões mineradoras, aumentando a concentração de renda e, assim, a desigualdade social” (COELHO, 2012, p. 20). E nessa relação de subordinação são criadas as condições de existência da área de sacrifício que "serve para se entender melhor como alguns lugares no mundo se tornam inviáveis à vida. Pela poluição são destinados a serem espaços-lixo da humanidade" (CASTRO, 2019, p. 26). A ação das mineradoras e de suas cadeias produtivas, que se multiplicam, atingem diretamente comunidades tradicionais que, historicamente, ocupam terras forjadas ancestralmente. Os empregos gerados, muitos em condições precárias e com adoecimentos, não podem ser a justificativa de "desenvolvimento" associada à expansão das mineradoras nas vidas locais que levam aos desastres e crimes socioambientais.

As pessoas estão condenadas a viver, seja pelas suas condições de pobreza, empurradas pela desigualdade social, ou seja porque tiveram seus territórios tradicionais, de vida e de trabalho, "invadidos pelos projetos de desenvolvimento", poluídos pelo despejo de materiais tóxicos (LERNER, 2011), de fábricas e do agronegócio, ou pelas operações portuárias que os acompanham, com seus riscos imprevisíveis e os desastres como o afogamento de 5.000 cabeças de gado no porto de Barcarena, que foi acompanhado da mortandade de peixes devido à inviabilidade do rio à vida, pois invadido pela poluição, produzindo essa imagem terrível de um cemitério de águas que exalava um cheiro infernal de matéria podre nas cidades do Conde, Vila dos Cabanos e Barcarena (CASTRO, 2019, p. 26) 
Não obstante as contradições sociais e as linhas programáticas dos movimentos sociais, há um consenso na complexidade do tema diante do avanço do sistema capitalista na região, percebido na monetização das relações e na cultura da exploração das vidas e do meio-ambiente. O maior desastre/crime ambiental da Amazônia, provocado pela Hydro-Alunorte em fevereiro de 2018, reforçou a necessária qualificação do debate e a urgência da contra-informação.

Os dados apresentados foram coletados em reuniões de trabalho, fóruns de debates, audiências públicas e seminários sobre desastres da mineração nos anos de 2016 e 2018, organizados por GETTAM/UFPA (Grupo de Estudo sobre Estado, Território, Trabalho e Mercados Globalizados), GESTERRA (Grupo de Estudo Território e Resistência na Amazônia) (GETTAM-UFPA), Movimento Barcarena Livre e IBASE. Também foram imprescindíveis, o trabalho de pesquisa da Agência Amazônia Real que conta com o foto jornalismo independente de Pedrosa Neto e Catarina Barbosa, cujas imagens ilustram esse artigo e muitas delas ganharam o mundo. Nessa mesma direção, destaco o trabalho dos professores de comunicação do GETTAM que vem se debruçando sobre o comportamento das mídias nos desastres na perspectiva crítica e, em especial, o silenciamento socialmente produzido das vozes das comunidades atingidas e dos movimentos socais.

/O artigo apoia-se nas racionalidades outras construídas pelos movimentos sociais em questão que problematizam os "efeitos-derrame" (GUDYNAS, 2016). Está baseado numa abordagem crítica e interdisciplinar na área da sociologia do desenvolvimento e nas discussões e participações dos movimentos em audiências públicas, assembleias, reuniões de trabalho e observações nas atuações das lideranças no período de 2017 a 2019. O artigo inicia fazendo uma contextualização de Barcarena como território de hegemonia da mineração e a comoditização dos processos sociais impõe suas estratégias e buscam invalidar outras perspectivas de atuação. Posteriormente, apresenta-se a força política da contrainformação como um exercício cumulativo das práticas educativas permeadas pelas atuações em rede e conhecimento coletivo. Em seguida, são referenciadas algumas ações de resistência e organização política. No final, serão feitas considerações finais com uma discussão sobre as novas agendas de debate. 


\section{Barcarena e a tensão diante das narrativas em disputas}

Os territórios amazônicos têm sido destruídos pelas grandes cadeias de produção global de commodities. O alvo são os territórios considerados estratégicos para a produção e logística da mobilidade do capital. São processos que ampliam as "pressões sobre as florestas, as águas, a terra e o subsolo" (ZHOURI, BOLADOS E EDNA CASTRO, 2016, p. 10) em decorrência da competitividade promovida pela guerra de commodities que protagonizaram um capítulo importante no mercado globalizado. Isso revela o quão é estratégico o papel dos recursos naturais na disputa geoeconômica e política. O conjunto desses processos são portadores de desastres socioambientais instituídos na dinâmica de expansão da reprodução concentração de riqueza, sentido maior da reprodução ampliada do capital. Além de ser nocivo ao trabalho humano por estar entre as atividades econômicas que mais matam e promovem graves acidentes de trabalho, os sistemas de produção da mineração são impactantes à saúde humana por estarem vinculados ao desequilíbrio do ecossistema, interferindo na dinâmica do tempo-espaço da vida natural, fundamentes do bemestar humano e na qualidade de vida (PORTO; PACHECO; LEROY, 2013) . A saúde ambiental, portanto, é decisiva para uma vida com dignidade e respeitando os indicadores da saúde coletiva.

Estudos anteriores sinalizavam para o aprofundamento dos desastres socioambientais no Brasil ${ }^{2}$. No entanto, os desastres de Mariana (2015) e Brumadinho (2019) em Minas Gerais com proporções planetárias quando considerados os efeitos, colocam o Brasil em alerta e o sistema de mineração, por sua vez, busca estratégias para continuar explorando e destruindo os territórios em que estão instalados e têm hegemonia política e econômica. Em Barcarena, a Hydro-Alunorte foi responsável por mais um desastre, constituindo-se no maior desastre socioambiental da Amazônia (CASTRO e CARMO, 2019): vazamento de

\footnotetext{
2 Com a recorrência e o volume de danos, riscos e crimes provocados pelos territórios da mineração em Minas Gerais (Samarco e Vale/BHP) e Pará (Hyro-Alunorte), o Brasil tornou-se o país com maiores desastres socioambientais do planeta nos últimos tempos (PASSARINHO, 2019). Os desastres/crimes ambientais ocorridos em Mariana, Brumadinho e Barcarena são emblemáticos para demonstrar a força da destruição de vidas em todos os sentidos.
} 
resíduos do beneficiamento da bauxita da bacia de rejeitos( DRS2) que causou danos irreparáveis à população de Barcarena, indicados por vários pesquisadores no Dossiê Desastres e Crimes da Mineração em Barcarena (CASTRO e CARMO, 2019).

O vazamento de substâncias tóxicas de bacias de rejeitos tem sido comum em Barcarena. A realidade do município aponta vários episódios sobre o tema. $\mathrm{O}$ município faz parte da região do país que possui bacias de rejeitos na categoria de risco alto, conforme mapa abaixo:

Mapa 1: Categorias de risco das barragens de mineração do Brasil.

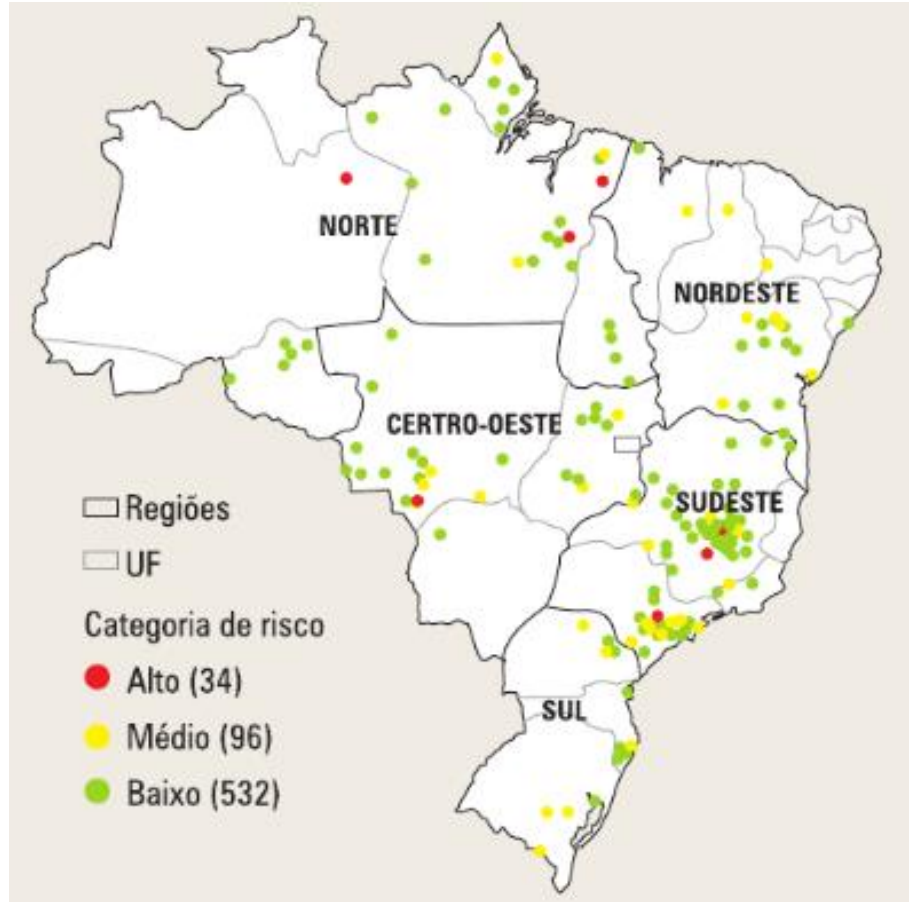

Fonte: DMPN - Cadastro Nacional das Barragens da Mineração.

Há uma questão estrutural dos desastres: a histórica contaminação das águas em Barcarena em decorrência das substâncias bioacumulativas tóxicas. Os trabalhos importantes da pesquisadora Simome Pereira constatam os efeitos dessas substâncias para saúde humana e ecossistemas (PEREIRA 2007; 2010; 2014). Os cursos dos rios, os furos e braços de rios estão comprometidos pelos rejeitos que são despejados nos rios.

"O rio Murucupi é um pequeno rio, com sua nascente dentro da área da Hydro-Alunorte, produtora de alumina e foz no Rio Barcarena, afluente do rio Pará próximo a ilha Trambioca, este pequeno rio é impactado com efluente de lama vermelha da bacia DRS1 da empresa na época de chuvas típicas da região. Este estudo avaliou as condições químicas do rio Murucupi em relação aos parâmetros físico-químicos e à presença de elementos químicos na água e suas correlações” (PEREIRA, 2019, p. 84) 
Com o vazamento da bacia de rejeitos da Hydro-Alunorte, uma lama tóxica invadiu comunidades tradicionais e contaminou rios, dentre eles o Mucurupi. As imagens abaixo revelam a proporção do desastre.

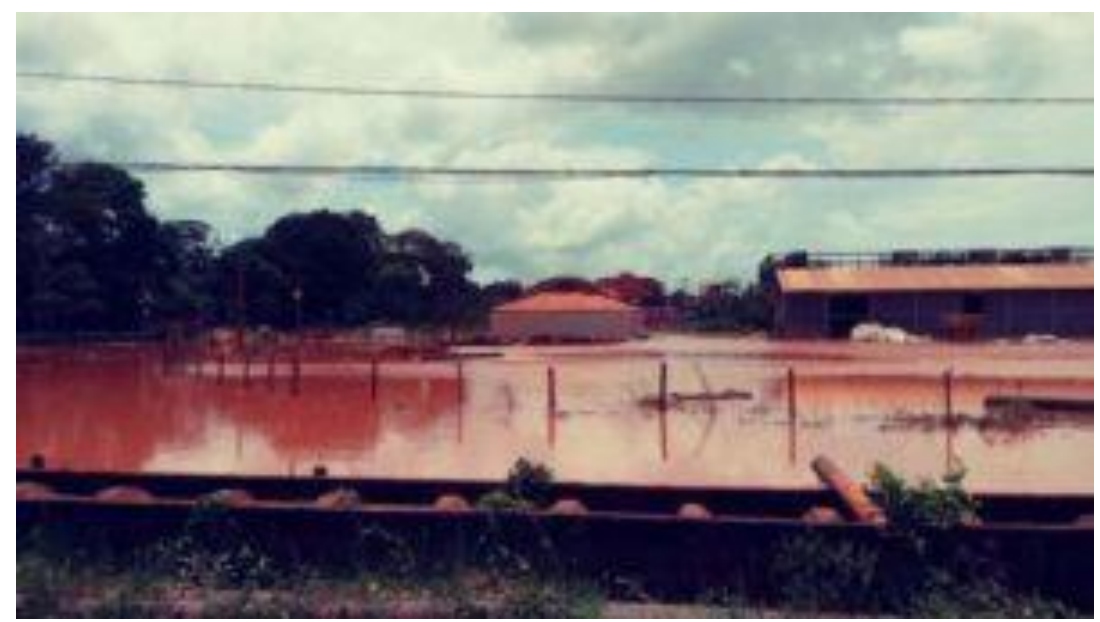

Foto: Instituto Evandro Chagas

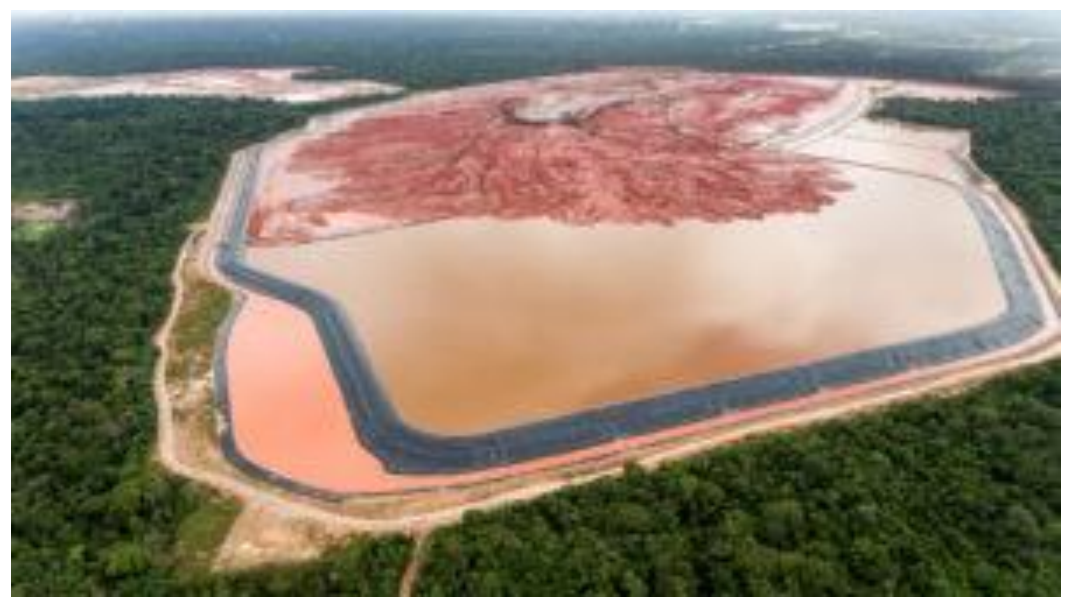

Foto: Pedrosa Neto/Amazônia Real 


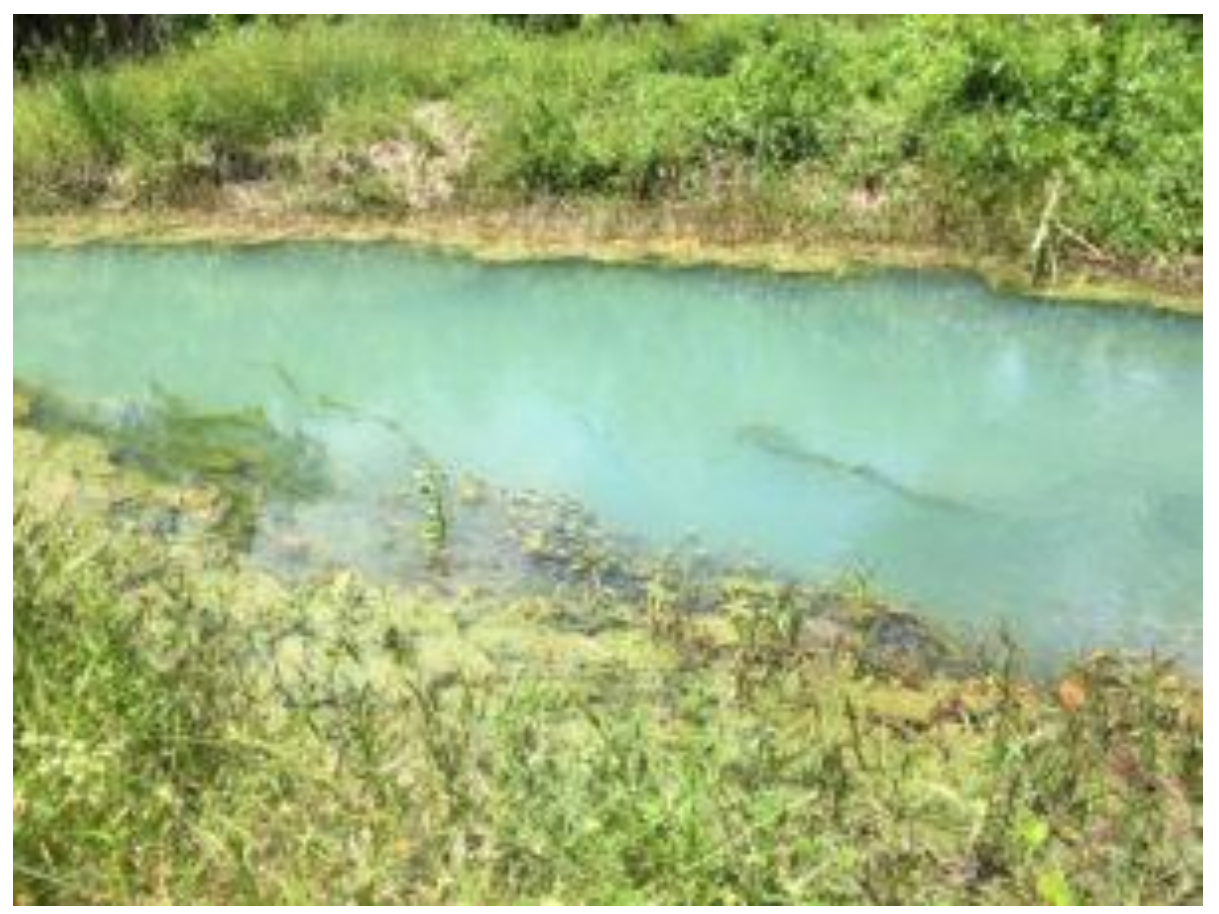

Foto: Catarina Barbosa/Amazônia Real)

A visão de gerenciamento de riscos da empresa Hydro-Alunorte não faz menção à questão ambiental e tão somente aos aspectos econômico-financeiros:

Continuaremos a garantir o valor de nosso portfólio comercial, protegendo as exposições de risco de preço nos negócios de usptream e downstream do grupo, principalmente resultantes de atrasos entre o processo de fabricação e o preço dos produtos para nossos clientes. (HYDRO, 2017).

As empresas mineradoras se valem desse expediente para legitimar uma governança hegemônica necessária para atendimento das demandas dos acionistas. Milanez e Santos (2013) analisam a conjugação neoextrativismo e neodesenvolvimentismo uma readequadação do poder econômico e político que privilegia a atuação das empresas com uso intensivo de tecnologia ancorados em processos que ampliam e instituir novos espaços transfronteiriças, notadamente vinculados às áreas de comunidades tradicionais, para garantir novas áreas de expansão do mercado que, por sua vez, agenciam novas logísticas de transporte. Soma-se a esta discussão as contribuições de Zhouri, Bolados e Castro (2016) quando as autoras reforçam que o neoextrativismo está relacionado à reprimarização da economia e aos programas globais que legitimam essa nova 
ofensiva na intensificação para uma trajetória voltada para crescimento econômico com perda de biodiversidade e poluições diversas variadas.

A financeirização da natureza e o mercado de terra baseados na lógica de mobilidade do capital são eixos baseados na capacidade de produção de commodities na região e na logística de escoamento de mercadorias (CASTRO, 2012; ZHOURI, BOLADOS, CASTRO , 2016). A compreensão da reestruturação produtiva presente nesse cenário e, ao mesmo tempo, os processos sociais e políticos dele resultante são vitais para a formulação de novos conhecimentos e informações que incrementam as agendas de lutas políticas.

\section{Conhecimento e Informação: produção social contra-hegemônica}

A força social do território que forja a reação dos grupos socialmente atingidos pelo capital. O território educa e politiza (CARMO, 2010) e a afirmação das suas territorialidades confirma também a força do saber das experiências construídas no cotidiano das relações sociais dos modos de vida das comunidades e grupos sociais. A emancipação social produzida na realidade dos conflitos socioambientais para garantira dos direitos territoriais. Nessa direção, é central revelar a perspectiva de análise adotada que se situa em duas ideias-força: $1^{0}$ ) A integração entre mineração(economia de desastres) e a recorrência de desastres, perfazendo "efeitos-derrame" como condição direta de regiões com cidades comoditizadas; $2^{0}$ ) A produção social da contrainformação é resultado do ambiente de disputa política que questiona o debate reduzido apenas em âmbito tecnológico, trazendo mediações sociopolíticas com vista a tensionar os problemas multidimensionais que envolvem e constituem o tema desastres.

A operação reflexiva dessas questões é prioritária na atuação dos movimentos sociais aqui mencionados (MAM, MAB e Movimento Barcarena Livre) a partir da construção social coletiva e das interações com as redes de grupos de pesquisa e entidades sociais. Vislumbra-se, dessa forma, a compreensão da totalidade social dos sujeitos envolvidos e a luta pelos seus direitos (CASTRO, 2012; ZHOURI, BOLADOS, CASTRO, 2016; CARMO et al, 2017). Na direção do que foi reafirmado sobre a totalidade do ser social atingido 
pelos desastres da mineração, há um fato de primeira ordem: a desterritorialização dos povos e comunidades. Trata-se de uma gestão territorial hegemônica para expansão econômica capitalista em Barcarena (HAESBAERT, 2004). Em decorrência disso, há o desequilíbrio dos ecossistemas com ataques e contaminação dos territórios que passam a ser dominados pelas cadeias produtivas dos empreendimentos. Florestas, águas, terras, modos de vida, trabalho locais são devastados por uma economia de desastres. Há uma correlação inevitável envolvendo mineração, desastres e acumulação (CHIAVEGATTO, 2019). Para Queiroz e Moraes (2019), a combinação entre exploração de recursos, rompimentos de bacias e volatilidade de preços é base desta economia. No mercado internacional, a gestão desses negócios implica diretamente nas estratégias locais de redução de custo e otimização dos recursos, implicando diretamente na segurança e no meio-ambiente.

\begin{abstract}
"Nesse momento, com as empresas comprometidas com os custos da expansão e tendo que vender o minério estocado em seus pátios, elas vão começar a cortar custos. E não é incomum que os primeiros cortes ocorram sobre o monitoramento de segurança. Então os projetos, muitas vezes realizados a toque de caixa (durante a alta dos preços), ficam ainda menos controlados nos períodos de baixa." (MILANEZ apud CHIAVEGATTO, 2019).
\end{abstract}

Dessa forma crítica e analítica, os movimentos sociais promoveram tensões importantes sobre o debate a respeito do sistema de mineração no Brasil. Suas linhas de reflexão apontam para a politização dos problemas da mineração que são disfarçados e encobertos por ações cosméticas (responsabilidade social). A desfaçatez é problematizada com a produção de conhecimentos em rede com universidades e entidades sociais e de contra- informação produzidos com códigos e símbolos da cultura e saberes locais, baseadas nos processos políticos da ofensiva contra o sistema capitalista da mineração. Em audiências públicas, manifestações populares, reuniões de trabalho é comum notar a presença de faixas e cartazes que denunciam, ironizam, politizam e desabafam toda uma carga de opressão e dominação presente na histórica exploração do espaço de Barcarena, o desterritorizando. Foi assim durante todo o período de maior atenção para o desastre da Hydro-Alunorte em Barcarena. Expressões como “assassina”, “culpada”, “morte”, “poluição”, “justiça”, “condenada” dentre outras desencadeiam múltiplas frentes de embate no campo político-ideológico por se 
tratar de expressões denunciativas que colocam em xeque a postura da empresa como sofisticada e requintada. Há um pensamento cristalizado das empresas de um passado com baixo poder de resistência e posicionamento da sociedade. As empresas continuam usando um esquema de gestão baseado no controle tecnológico para uma realidade viva que vem se transformando pelas tensões em curso em maior ou menor grau. Ainda assim, os movimentos sociais tem tido vigor na busca da emancipação política diante das novas investidas do capital minerador. As imagens ilustram essas iniciativas

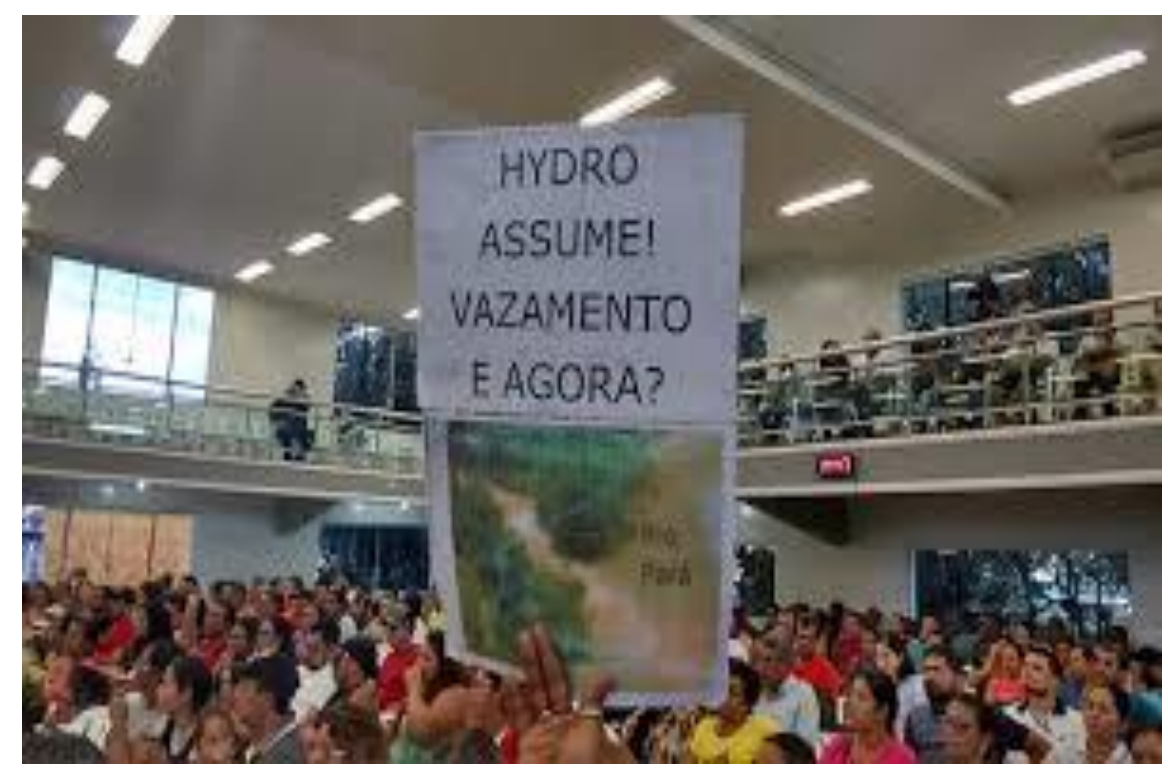

Foto: Audiência Pública em Barcarena - 22/03/2018 (Pedrosa Neto/Amazônia Real)

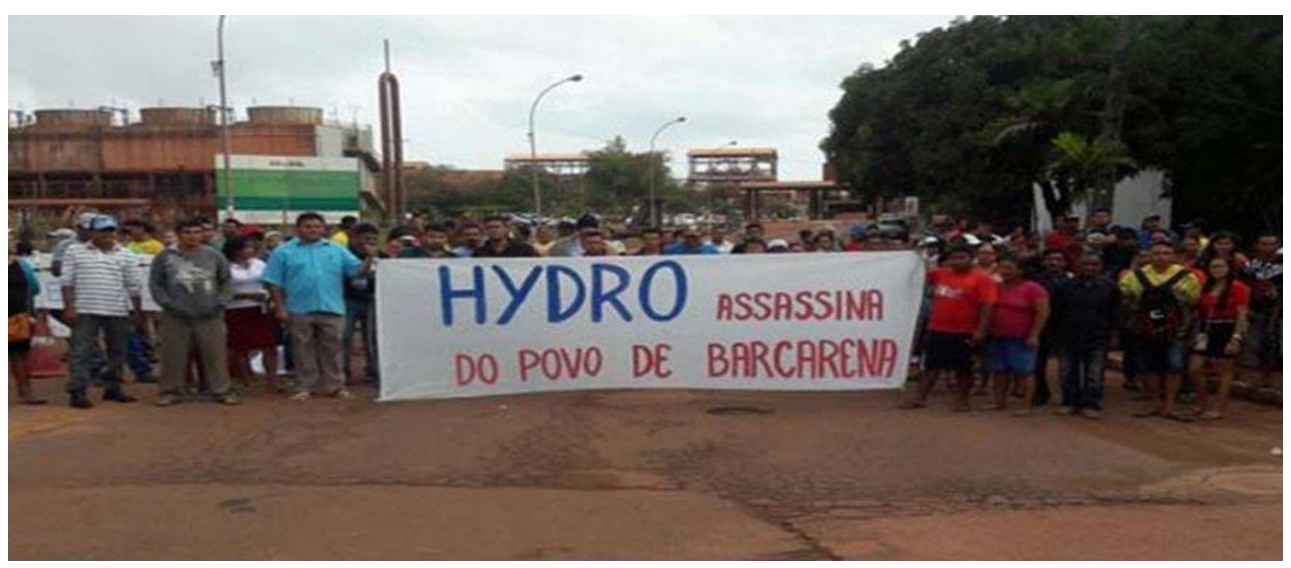

Foto: Manifestação em frente à Hydro-Alunorte (Pedrosa Neto/Amazônia Real) 


\section{Resistências diante da Injustiça Ambiental}

Os territórios são espaços eminentemente políticos. A deslegitimação da governança das mineradoras é um dos focos do debate. O mapa abaixo revela o grau de desestruturação provocado pelos empreendimentos na região periférica do capitalismo.

\section{Mapa de Conflitos Envolvendo Injustiça Ambiental e Saúde no Brasil}

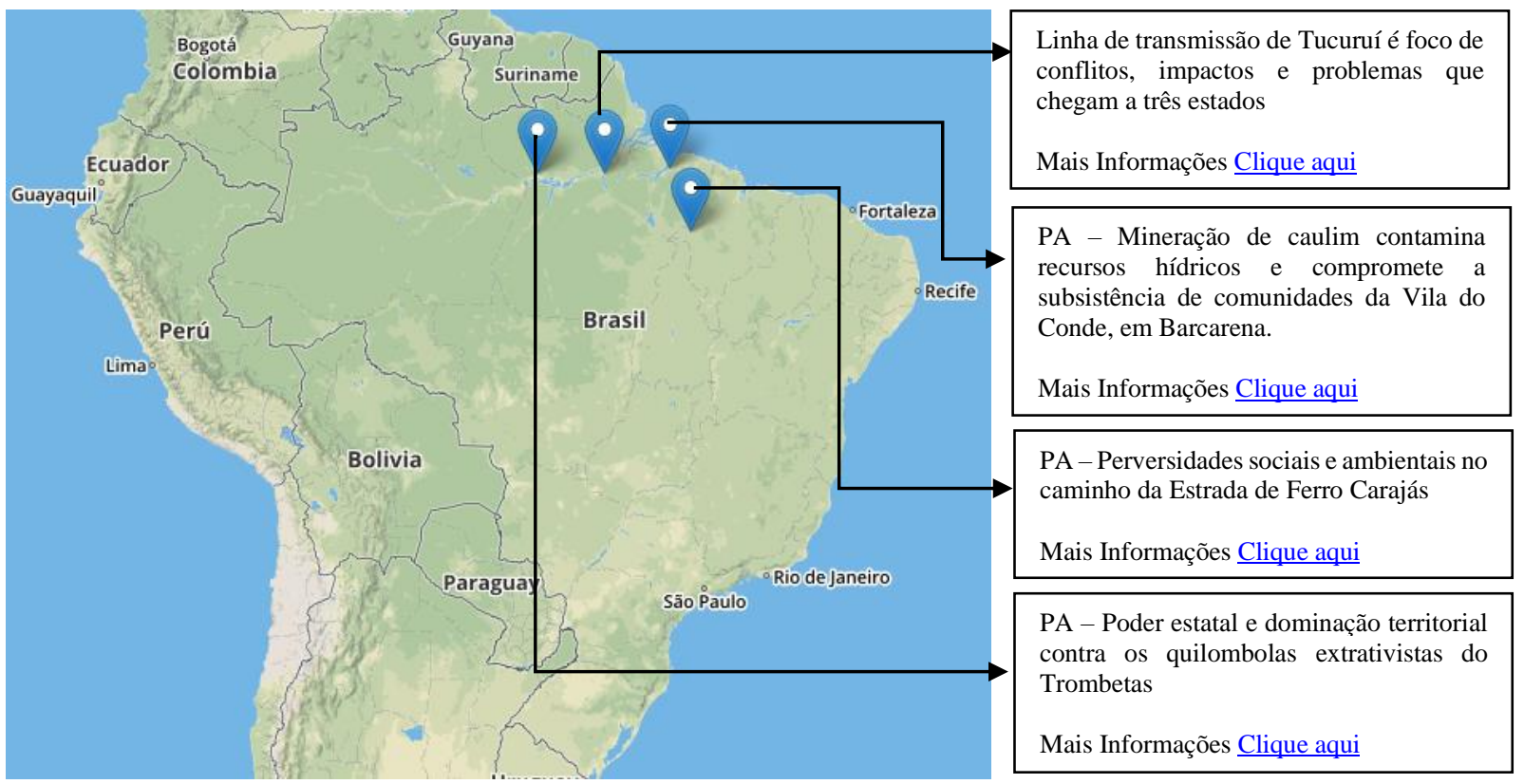

Fonte: NEEPES e Fundação Osvaldo Cruz.

O mapa revela os territórios de desastres. Os desastres são produzidos socialmente e, ao mesmo tempo, exigem a recomposição do sentido de resistência nas bases dos territórios de luta (VALENCIO, 2007). Dessa forma, optou-se pela percepção política e social das consequências dos desastres:

\footnotetext{
"Os impactos socioambientais da mineração não são simples, nem espacialmente limitados, muito menos temporalmente restritos. Na verdade, muitos deles são ecologicamente complexos, espacialmente amplos e, por serem irreversíveis, temporalmente permanentes". (MILANEZ, 2017, p. 94)
}

As narrativas produzidas por moradores, lideranças, trabalhadores, ribeirinhos e comunidades tradicionais estão inscritos na realidade da produção social dos desastres socioambientais em Barcarena. Os movimentos sociais são forças políticas de produção de contrainformação que encontra mecanismos de enfrentamento via comunicação verbal e não-verbal. Optam por uma organização 
sociopolítica plural com articulação em rede (MAM, MAB e MST). Diferentemente, de como são produzidas as informações midiatizadas. Durante a veiculação do desastre da Hydro-Alunorte, a mídia tratou os grupos sociais, moradores e movimentos sociais de maneira despolitizada. Autores que se debruçaram sobre o tema assim analisam esse fato, quando se referem à forma de a cobertura da mídia sobre o desastre da Hydro-Alunorte no que consiste na percepção dos diretamente atingidos

\begin{abstract}
As fontes populares aparecem em grande parte sem identificação, inominados ou classificados pelo caráter de vulnerabilidade da situação - "desempregado", como escrito na legenda, em mais de um caso. O que se estende para as falas e imagens selecionadas, por situações de desespero - o homem doente, a mulher de joelhos. As fontes populares são destacadas assim como pessoas sem agência - sem capacidade de agir e decidir seu destino (BRAGANÇA, STEINBRENNER, NETO, 2019, p. 134)
\end{abstract}

A imagem abaixo revela a forma como a mídia televisa trata os sujeitos atingidos pela mineração. Há uma tônica de não nominá-los e quando fazem são usados expressões desempregados, moradores. Os autores são assertivos na análise crítica sobre a maneira e o conteúdo onde "persistentes colonialidades, que excluem e inferiorizam os mais vulneráveis, invisibilizam outras versões e visões - dos homens e mulheres pobres que moram em lugares periféricos e lutam sob constante risco” (BRAGANÇA, STEINBRENNER, NETO, 2019, p.133). 


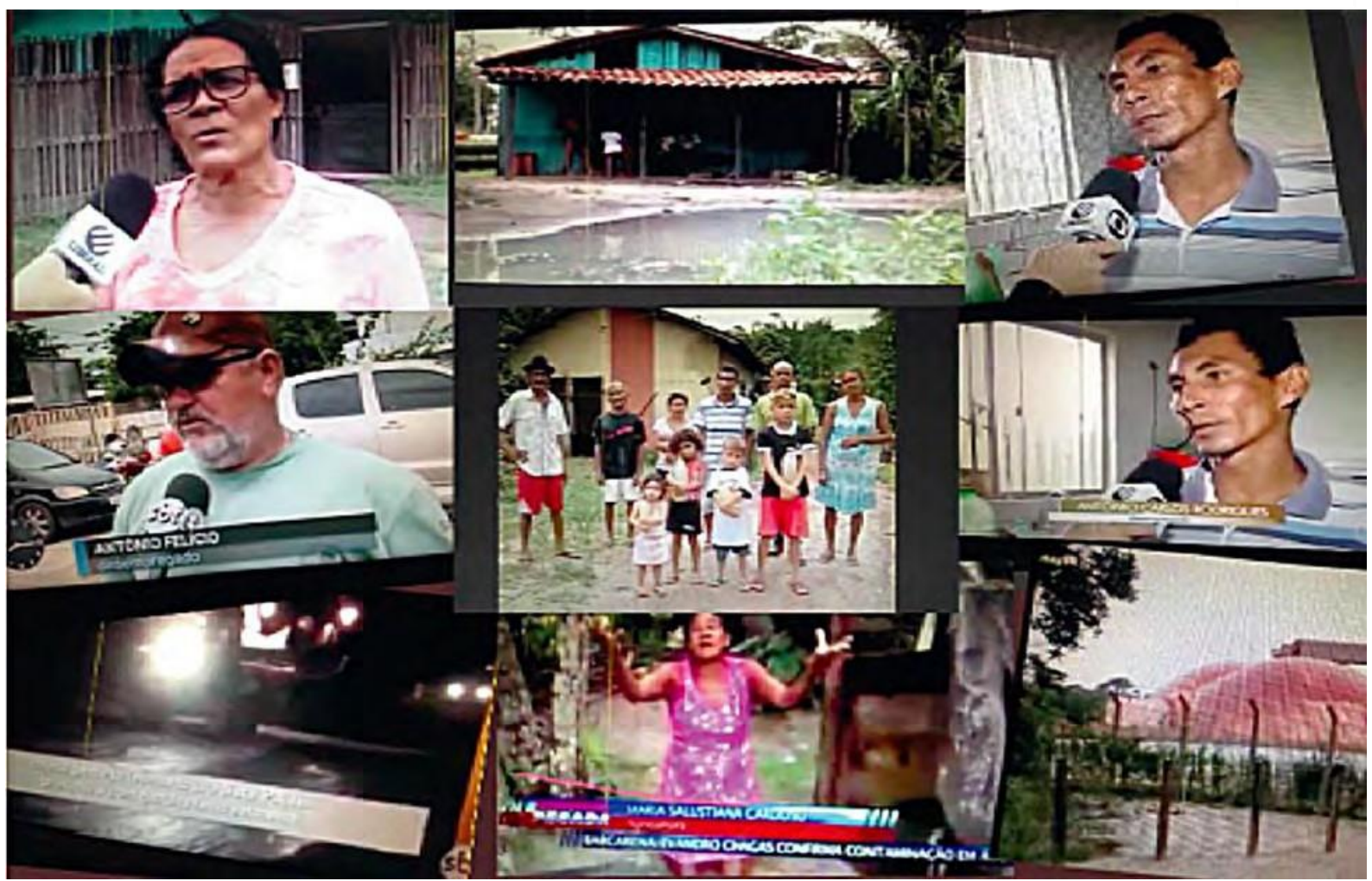

Fonte: BRAGANÇA, STEINBRENNER, NETO, 2019, p.133

A produção de outras narrativas que fissure a "bolha tecnológica" da mineração e dê visibilidade e autonomia aos sujeitos políticos é fundamental para a politização do debate como forma de pautar discussões que joguem luz sobre a ineficiência do sistema de mineração no Brasil e a responsabilidade do Estado neste processo. Portanto, falar de "desastres", “crime”, “dano”, "risco", "adoecimentos”, “insustentável”, "mortes”, “antimineração” é denúncia e, ao mesmo tempo, trabalha para a produção de sentidos da mineração que contrariem àqueles agenciados pela hegemonia do mercado. Os embates travados por empresas mineradoras e movimentos sociais no território de Barcarena são demonstrações do encontro-choque envolvendo formas de apropriação no campo de força em que as narrativas são acionadas com repertórios diversos: sustentável e insustentável, segurança e insegurança, saúde e morte, responsabilidade social e cooptação, progresso e retrocesso, maior do mundo e "assassina" são formas de afirmação das territorialidades em disputa em Barcarena. A imagem acena nessa direção de denúncia e enfrentamento. 


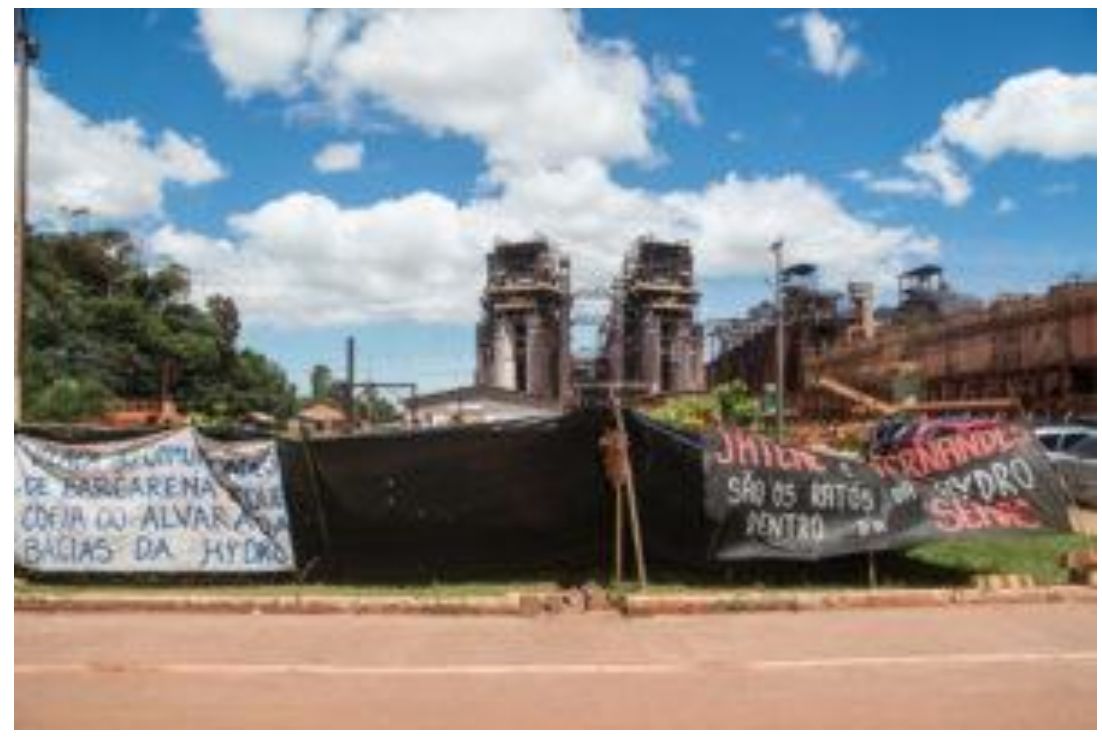

Foto: Faixas de protesto e denúncia nas Hydro-Alunorte (Pedrosa

Neto/Amazônia Real)

Trata-se de grupos sociais com visão política da injustiça ambiental que denunciam, recorrentemente, os desastres/crimes ambientais e anunciam novas ações de enfrentamento ao sistema de mineração. Foram esses grupos que se posicionaram criticamente nas diversas audiências públicas, sessões na Assembleia Legislativa e reuniões de trabalho. Na correlação de forças, a questãocentral é: Não dá para ter mediação com empresas que produzem mortes e doenças. Este é o projeto da mineração. O campo democrático popular conta com movimentos sociais e comunidades tradicionais e ribeirinhas que insurgem em outro projeto que valoriza a vida, a ancestralidade e a floresta em pé.

\section{Considerações Finais}

Importa considerar que a produção dos desastres faz parte da dinâmica da mineração. Dessa consideração, apoiada politicamente pelos movimentos sociais, apreende-se que a desestruturação socioespacial vivida por comunidades tradicionais e grupos sociais se constitui em espaços marcados pela governança da mineração em cadeias globo-locais. Diferentemente da lógica empresarial, os movimentos sociais entendem que o enfrentamento ao padrão mínero-logístico passa pela discussão dos temas vulnerabilidade social e precarização das relações 
Revista Brasileira de História \& Ciências Sociais - RBHCS

Vol. $12 \mathrm{~N}^{\circ} 23$, Janeiro - Junho de 2020

sociais em decorrência de operações industriais que operam em circunstâncias de violência social e ambiental.

Tais processos precisam ser apreendidos na perspectiva histórica e diante dos novos processos de ocupação, apropriação e uso do território a partir da realidade socioeconômica local e suas interações com os mercados globais e internacionais, mediante a visão multiescalar e multidimensional em curso, a qual implica em ampliar o contexto da abordagem para melhor captura da complexidade social e das disputas que descentram as relações de poder. Nesta direção, a gestão territorial sendo uma construção social conflituosa e inacabada, está sempre se refazendo quando processos de reestruturação econômica redesenham os espaços e as territorialidades humanas, como vem ocorrendo em Barcarena, cujo município é considerado distrito industrial na Amazônia Oriental, sendo, portanto fundamental para geoestratégia global da economia de mineração na região. Mais do que isso, Barcarena é uma zona de sacrifício (ZHOURI; BOLADOS e CASTRO, 2016). Ou seja, em Barcarena tudo pode para gerar divisas e lucro para o capital, implicando em suportar desastres socioambientais, desregulamentação, ausência de fiscalização, doenças, mortes, pois todos são considerados como efeitos colaterais do "desenvolvimento".

Os desastres provocados por grandes mineradoras em Mariana e Brumadinho, que aumentaram o sentimento de antimineração no país, cooperaram para a recomposição do campo. Neste sentido, o slogan "Somos todos atingidos" ganha importância porque coloca na cena contemporânea brasileira os limites da mineração, ganhando um importante efeito de politização. Por outro lado, analisa-se as estratégias da empresa Hydro-Alunorte diante deste cenário de ampliação das críticas e sentimento antimineração. Essas estratégias constantes em seus documentos oficiais (relatórios, boletins e sites coorporativos). O protagonismo dos movimentos sociais tem feito diferença no campo de disputa política. Há linha orientadora da ação-reflexão, construída coletivamente, que está centrada na percepção ampla dos que sentem a vida sendo destruída pelos desastres e a necessidade de lutar e garantir a enunciação da palavra daqueles que lutam. As narrativas que buscam identificar e descrever percursos históricos e as expressões e vivências com seus antecedentes e conteúdos compõem o quadro das contradições e avanços perfazendo a matriz 
formativa e social desenvolvida coletivamente, cuja tônica é a contrainformação, tendo como foco principal as relações históricas e sociais dos movimentos sociais.

\section{Referências}

ALEPA. Comissão Parlamentar de Inquérito: Danos ambientais na bacia hidrográfica do rio Pará. Relatório Final. Belém: Alepa, 2018.

BARCARENA LIVRE. Barcarena Livre Informa: 37 anos de desastres socioambientais em Barcarena. Belém: UFPA; Rio de Janeiro: IBASE, 2016.

BRAGANÇA, Pedro L. de. STEINBRENNER, Rosane A. NETO, Guilherme G. A cobertura do vazamento da Hydro Alunorte em Barcarena. In: CASTRO, E.; CARMO, E. D. (Ogrs). Dossiê: Desastres e crimes da mineração em Barcarena. Belém: NAEA: UFPA, 2019.

CARMO, E. D. Desastres e tensões em Barcarena à luz de disputas territoriais. In: CASTRO, E. (Org.). Territórios em Transformação: saberes, rupturas e colonialidade. Belém: NAEA, 2017. p. 65-80.

CARMO, E. D.; CASTRO, E.; PATRÍCIO, J. Mineração e neo-extrativismo de commodities e conflitos. Novos Cadernos NAEA, v. 18, n. 3, p. 51-71, 2015.

CARMO, E. et al. Barcarena livre: resistência e lutas de comunidades tradicionais frente aos desastres socioambientais da mineração. In: CASTRO, E. (Org.). Territórios em Transformação: saberes, rupturas e colonialidade. Belém: NAEA, 2017. p. 365-388.

CASTRO, E. (Org.). Territórios em Transformação: saberes, rupturas e colonialidade. Belém: NAEA, 2017.

CASTRO, E. Estratégias de expansão territorial de empresas minerais na Amazônia, desastres socioambientais e "zonas de sacrifício". In: CASTRO, E.; CARMO, E. D. (Ogrs). Dossiê: Desastres e crimes da mineração em Barcarena. Belém: NAEA: UFPA, 2019.

CASTRO, E. Expansão da fronteira, megaprojetos de infraestrutura e integração sul-americana. Caderno CRH, Salvador, v. 25, n. 64, p. 45-61, jan./abr., 2012.

CASTRO, E.; CARMO, E. D. (Ogrs). Dossiê: Desastres e crimes da mineração em Barcarena. Belém: NAEA: UFPA, 2019.

CHIAVEGATTO, JOÃO. A3 Dossiê: A economia do desastre. Juiz de Fora, 2019. Disponível em: https://www2.ufjf.br/noticias/2019/02/13/a3-dossie-aeconomia-do-desastre/, acesso em: 30 de março de 2020.

COELHO, Tádzio P. Mineração e dependência no quadrilátero ferríferoaquífero: o discurso do desenvolvimento minerador e o Projeto Apolo.

Dissertação (mestrado) - Universidade do Estado do Rio de Janeiro, Instituto de Filosofia e Ciências Humanas. Rio de Janeiro, 2012.

DNPM - Departamento Nacional de Produção Mineral. Classificação das barragens de mineração. Belém: DNPM, 2016. Disponível em: 
http://www.anm.gov.br/assuntos/barragens/arquivos-arragens/

CADASTRO\%2ONACIONAL\%20DE\%20BARRAGENS_2016\%20_FINAL\%200 6-01-2017.pdf. Acesso em: 15 maio 2019.

GUDYNAS, E. Extractivismos en America der Sur: conceptos y sus efectos derrame. In: A. Zhouri, P. Bolados, E. Castro (eds.). Mineração na América do Sul: neoextrativismo e lutas territoriais. São Paulo: Ed. Annablume, 2016. p. 23-43.

HAESBAERT, R. O mito da desterritorialização: do "fim dos territórios” à multiterritorialidade. Rio de Janeiro: Bertrand Brasil, 2004.

HAZEU, M. T., COSTA, S. M. G. DA, \& FIALHO NASCIMENTO, N. S. (2019). Comunidades tradicionais e sindicatos em conflito com estado e capital em Barcarena (PA). Argumentum, 11(1), 173-187.

HYDRO. Estratégias e metas, 2017b. Disponível em: https://www.hydro.com/en/investors/reports/annual-report-2017/strategyand-targets/. Acesso em: 14 abr. 2019.

MILANEZ, B.; SANTOS, R. Neodesenvolvimentismo e neoextrativismo: duas faces da mesma moeda? In: ENCONTRO ANUAL DA ANPOCS, 37, 2013, Sãp Paulo. Anais ... São Paulo: ANPOCS, 2013. Disponível em: http://www.ufjf.br/poemas/files/2014/o7/Milanez-2013Neodesenvolvimentismo-e-neoextrativismo-duas-faces-da-mesma-moeda.pdf. Acesso em: 19 jan. 2019.

NEEPES/ENSP/FIOCRUZ. Mapa de Conflitos Envolvendo Injustiça Ambiental e Saúde no Brasil. Disponível em: http://mapadeconflitos.ensp.fiocruz.br/?populacao=agricultoresfamiliares\&uf=pa\&s=barcarena\&post_types=conflito. Acesso em: 20 de Jan. 2020

OBIND - Observatório dos Direitos e Políticas Indígenas. Amazônia Real: “O igarapé morreu, não tem mais peixe”, diz moradora sobre impactos em Barcarena. Brasília, 2018. Disponível em:

http://obind.eco.br/2018/05/21/amazonia-real-o-igarape-morreu-nao-temmais-peixe-diz-moradora-sobre-impactos-em-barcarena. Acesso em: 13 de Jan. 2020

PASSARINHO, N. Tragédia com barragem da Vale em Brumadinho pode ser a pior no mundo em 3 décadas. BBC NEWS, Londres, 29 de janeiro de 2019. Disponível em: https://www.bbc.com/portuguese/brasil-47034499. Acesso em: 25 mar. 2019.

PEREIRA, S. F. P. Desastres Sócio-Étnico-Técnico-Ambientais em Barcarena. CASTRO, E.; CARMO, E. D. (Ogrs). Dossiê: Desastres e crimes da mineração em Barcarena. Belém: NAEA: UFPA, 2019.

PEREIRA, S. F. P. Estudo da qualidade da água de consumo de moradores do município de Barcarena - Pa. Belém: UFPA, LAQUANAM, 2014 .

PEREIRA, S. F. P. Estudo preliminar dos níveis de contaminação Ambiental provocado por vazamento de efluente da Imerys rio capim caulim na região de vila do conde - Barcarena - Pa. Belém: UFPA, LAQUANAM, 2007. (Relatório). 
PEREIRA, S. F. P.; OLIVEIRA, G. F. Estudos químico-ambientais de recursos hídricos afetados por vazamento de caulim em Barcarena-Pa. In: SEMINÁRIO INTERNACIONAL - AMAZÔNIA E FRONTEIRAS DO

CONHECIMENTO, II, 2010, Belém. Anais ... Belém: NAEA, 2010.

PORTO, M.; PACHECO, T.; LEROY, J. P. Injustiça Ambiental e Saúde no Brasil: o Mapa de Conflitos. Rio de Janeiro: Editora Fiocruz, 2013.

QUEIROZ, H. A.; MORAES, V. R. O. . Mineração e Capitalismo no Vale do Rio Doce: produção destrutiva, rompimento de barragens e estratégias de reparação. In: XIII Encontro Nacional da Sociedade Brasileira de Economia Ecológica, 2019, Campinas. Vale do Rio Doce: produção destrutiva, rompimento de barragens e estratégias de reparação., 2019. p. 1-20. RAFFESTIN, Claude. Por uma Geografia do Poder. São Paulo: Ática, 1993. SANTOS, M.; SILVEIRA, M.L. O Brasil: território e sociedade no início do século XXI. 6.ed., Rio de Janeiro: Record, 2004.

SANTOS, Milton. A natureza do espaço. Técnica e tempo. Razão e emoção. São Paulo: Hucitec, 1996.

SAQUET, M. A. Abordagens e concepções sobre território. São Paulo: Expressão Popular, 2007.

SIQUEIRA, V. Alunorte: Uma história de sucesso. Belém: Artes Gráficas e Editora, 2010.

ZHOURI, A. BOLADOS, P. CASTRO, E.(Orgs). Mineração na América do Sul: neoextrativismo e lutas territoriais (1a ed.). Coleção Cidadania e Meio Ambiente. São Paulo: Annablume, 2016. 